\title{
Overall survival in hematopoietic stem cell transplantation is correlated with the Number butnotwith the Age of Red Blood Cells Transfused
}

\author{
Fleur M Aung ${ }^{1 *}$, Roland L Bassett ${ }^{2}$, Benjamin Lichtiger ${ }^{1}$, Chitra Hosing ${ }^{3}$, Emil J Freireich ${ }^{4}$ and Issa Khouri ${ }^{3}$ \\ ${ }^{* 1}$ Departments of Laboratory Medicine, The University of Texas MD Anderson Cancer Center, Houston, Texas \\ ${ }^{2}$ Departments ofBiostatistics, The University of Texas MD Anderson Cancer Center, Houston, Texas \\ ${ }^{3}$ Departments ofStem Cell Transplantation,The University of Texas MD Anderson Cancer Center, Houston, Texas \\ ${ }^{4}$ Departments of Leukemia, The University of Texas MD Anderson Cancer Center, Houston, Texas
}

Received: 27 October, 2017; Accepted: 09 November, 2017; Published: 29 December, 2017

*Corresponding author: Fleur M Aung, Department of Laboratory Medicine, Unit 0800, 1515 Holcombe Blvd, Houston, Texas 75088, USA, Tel: (713) 792-8630, Fax: (713) 792-2634; E-mail: fmaung@mdanderson.org

\begin{abstract}
Red blood cells (RBC) undergo biochemical and morphologic changes during storage and the changes known as "storage lesion" have raised concerns that RBCs stored for lengthy periods could increase mortality risks in patients receiving transfusions.We sought to analyze the association between aged RBCs and intensive care unit admissions, short-term and long-term survivals of patients undergoing hematopoietic stem cell transplantation (HSCT) and the association between overall survival and the number of RBCs transfused up to 100 days after HSCT. We reviewed the data from the Blood Bank database files from November 2008 to December 2009 for 334HSCT patientswho were alive 100 days after HSCT at the University of Texas MD Anderson Cancer Center. The patients were categorized into ICU vs. non-ICU patients after HSCT. We compared the age of RBCs, units of RBCs transfused and patients admitted to the ICU vs. non-ICU patients after HSCT. We found that the number of RBCs transfused correlated with overall survival and not with the age of the red cells transfused before and after HSCT.For both categories of patients: ICU vs. non-ICU patients, our retrospective analysis noted that those who received the most RBC transfusions had the worst survival.
\end{abstract}

\section{Introduction}

Red blood cells (RBCs) undergo well-documented biochemical and morphologic changes during storage. These "storage lesions," 1-14and have raised concerns that stored older RBCs could increase mortality risk in patients receiving RBC transfusion. Donor RBCs contain a mixed population of cells ranging from newly formed reticulocytes to 120-day-old RBCs at the time of donation, and it has not been established with certainty whetherstorage lesions affect different stages of maturity equally.9Prolong storage of RBCs results in increased oxygen affinity after 14 days of storage due to progressive consumption of the high-energy phosphate (2,3-diphophoglycerate 2,3-DPG), decreased activity of most enzymes involved in energy metabolism (metabolic dysregulation), accumulation of reactive oxygen species (ROS), protein fragmentation and impairment of the band 3 transport metabolon, preferential loss of certain lipids and enrichment of others in the membrane fraction with exacerbation of membrane loss (vesiculation). There is uncertainty to the actual effectiveness and damage that allogeneic blood can cause to the transfused patient.13, 14Theprimary aim of blood storage in the United States has been to extend the storage life of a preciousand perishable product with the use of additive storage solutions (AS-1, AS-3, AS-5 or AS-7) to maximize its availability such as the using the oldest stored blood first to avoid wasting the blood. However, the clinical consequences of transfusion of aged RBCs remain unclear for patients undergoing hematopoietic stem cell transplantation (HSCT).

\section{Objectives}

The primary objective of the current study was to analyze the association between the age of RBCs transfused before and after HSCT and intensive care unit (ICU) admission as well as short-term (100 days after transplant) and long-term (>100 days after transplant) overall survival rates after HSCT. The secondary objective was to analyze the association between overallsurvival ratesand the number of RBC units transfused up to 100 days after HSCT.

\section{Methods}

\section{Study Design}

The retrospective study design was approved by The University of TexasMD Anderson Cancer Center Institutional Review Board. Data were collected from the Blood Bank and Stem Cell and Cellular Therapy data-basesof our institution as well as patients' electronic medical records.The 2008-2009 Blood Bank records were reviewed for adult and pediatric patients who had undergone HSCT. All data onRBCs transfused at MD AndersonCancer Center before (D-100 to D-1) and after (D0 to $D+100$ ) were included. Patients who had received a mixture of newer and agedRBCs were included in the study. For our analysis, the age of RBCs transfused was grouped using three cutoff points: 
RBCs aged $<14$ days or $>14$ days, RBCs aged $<21$ days or $>21$ days and $\mathrm{RBC}$ aged $<28$ days or $>28$ days.Patients were grouped by ICU admissions: those admitted to the ICU up to HSCT day+100 and those not admitted to the ICU during this period. Because many patients had acute myeloid leukemia, a subgroup analysis of these patients was also performed.

\section{Statistical Analysis}

The Fisher's exact test was used to compare the distribution of categorical variables between patients who did and did not receive aged RBCs (for each age distinction) and between patients admitted or not admitted to the ICU.The Kaplan-Meier methodwas used to estimate the distribution of overall survival rate from the date of HSCT, and distributions were compared using the log-rank test. Cox proportional hazards regression was also used to assess the relationship between overall survival and continuous variables. P-values of less than 0.05 were considered statistically significant. No adjustment was made for multiple testing. Analyses were performed for all patients, in the cohort and then repeated for the subset of patients with AML (R version

\subsection{1).}

\section{Results}

We identified a total of 397 patients who underwent HSCT during that time periodstudied and of those, 335 (84\%) were alive at HSCT day+100. Among these 335 patients (199male, 136 female), six $(0.6 \%)$ were under the age of 6 years.The median age was52 years (range,2-72 years).Most patients(74\%) werewhite and received peripheral hematopoietic progenitor cells $(n=212$; $63 \%)$ and an ABO mismatched graft $(n=215 ; 64 \%)$.All of the major ABO incompatible grafts were RBCs depleted. Nearly half of the patients had been diagnosed with AML. Other common diagnoses were lymphoma, chronic lymphocytic leukemia and acute lymphocytic leukemia (Table 1).There were no patientswith benign hematologic issues (e.g. sickle cell disease) in this study. Overall, patients had received a total of 1869 RBC units (median, 3 units; range, 0-39 units) before HSCT and 3649 RBC units (median, 7 units; range, 0-112 units) after HSCT (Table 2). More specific ages of the units of RBCs transfused before and after HSCT are shown in (Table 3).

Table 1: Clinical Characteristics of HSCT patients (total vs. ICU vs.Non-ICU) alive at post-transplant D+100

\begin{tabular}{|c|c|c|c|c|}
\hline & Total $n=335(\%)$ & $\begin{array}{l}\text { Admitted to ICU } \\
n=27(\%)\end{array}$ & $\begin{array}{l}\text { Not Admitted to } \\
\text { ICU } n=308(\%)\end{array}$ & \\
\hline \multicolumn{5}{|l|}{ Sex } \\
\hline Male & $199(59)$ & $16(59)$ & $183(60)$ & 1 \\
\hline Female & $136(41)$ & $11(41)$ & $125(40)$ & \\
\hline Median Age (range) & $52(2-72)$ & $51(20-70)$ & $52(2-72)$ & 0.66 \\
\hline Race/Ethnicity & & & & 0.28 \\
\hline White & $249(74)$ & $20(74)$ & $9(74)$ & \\
\hline Hispanic & $58(17)$ & $3(11)$ & $55(18)$ & \\
\hline African American & $14(4)$ & $3(11)$ & $11(3.6)$ & \\
\hline Asian & $13(3.8)$ & $1(8)$ & $12(4)$ & \\
\hline Unknown & $1(0.2)$ & 0 & $1(0.3)$ & \\
\hline Diagnosis & & & & 0.25 \\
\hline AML & $162(48)$ & $11(41)$ & $151(49)$ & \\
\hline CML/MPD & $24(7)$ & $2(7)$ & $22(7)$ & \\
\hline ALL & $35(10)$ & $5(18)$ & $30(10)$ & \\
\hline CLL & $40(12)$ & $4(15)$ & $36(12)$ & \\
\hline Lymphoma/Hodgkin's disease & $61(19)$ & $3(11)$ & $58(19)$ & \\
\hline Myeloma & $7(2)$ & $1(4)$ & $6(2)$ & \\
\hline Aplastic Anemia & $4(1)$ & 00 & $4(1)$ & \\
\hline Non-hematologic disorders & $2(1)$ & $1(4)$ & $1(0.3)$ & \\
\hline Graft Source & & & & 0.43 \\
\hline Peripheral stem cell & $227(68)$ & $16(59)$ & $211(69)$ & \\
\hline Marrow & $67(20)$ & $8(30)$ & $59(19)$ & \\
\hline Cord blood & $41(12)$ & $3(11)$ & $38(12)$ & \\
\hline
\end{tabular}




\begin{tabular}{|c|c|c|c|c|}
\hline Conditioning regimen & & & & \multirow[b]{3}{*}{0.18} \\
\hline \multicolumn{4}{|c|}{ HLA Match Grade (Peripheral stem cell \& Marrow) } & \\
\hline 8/8 (HLA-A, -B,-C, -DR) & $274(94)$ & $20(83)$ & $253(94)$ & \\
\hline 7/8 (HLA-A, -B, -C, -DR) & $12(4)$ & $2(8)$ & $10(4)$ & \\
\hline Haploidentical & $9(3)$ & $2(8)$ & $7(3)$ & \\
\hline \multicolumn{5}{|l|}{ Cords } \\
\hline$>4 / 6$ (HLA-A, -B, -DR) & $41(100)$ & $3(100)$ & $38(100)$ & \\
\hline Myeloablative-Reduce intensity conditioning & $270(80)$ & $22(81)$ & $248(80)$ & 0.48 \\
\hline Non-Myeloablative & $65(20)$ & $5(19)$ & $60(20)$ & \\
\hline ABO-matched & & & & 0.4 \\
\hline ABO-matched & $120(36)$ & $12(44)$ & $108(35)$ & \\
\hline ABO-mismatched & $215(64)$ & $15(56)$ & $200(65)$ & \\
\hline Major mismatched & $132(61)$ & $10(67)$ & $122(61)$ & \\
\hline Minor mismatched & $83(39)$ & $5(33)$ & $78(39)$ & \\
\hline Engrafted & $328(98)$ & $26(96)$ & $302(98)$ & 0.45 \\
\hline Absolute Neutrophil count (ANC)/uL & $12(0-43)$ & $14(7-24)$ & $12(0-43)$ & 0.13 \\
\hline Median Platelet count (uL) & $16(0-203)$ & $17(0-63)$ & $15(0-203)$ & 0.09 \\
\hline Alive @ last follow-up & $137(41)$ & $2(7)$ & $135(44)$ & 0.0001 \\
\hline $\begin{array}{c}\text { Median number of days since transplantation at } \\
\text { last follow-up(range) }\end{array}$ & $1567(175-2203)$ & $1819 / 1901$ & $1556(175-2203)$ & \\
\hline
\end{tabular}

Table 2: RBC units transfused to patients before and after hematopoietic stem cell transplantation (HSCT) who werealivealive 100 days after HSCT, stratified by whether or not they admitted to the intensive care unit (ICU)

\begin{tabular}{|l|c|c|c|c|c|c|c|c|c|c|}
\hline RBC units transfused & \multicolumn{3}{|c|}{ Total (n=335) } & \multicolumn{3}{c|}{ Admitted to ICU (n=27) } & \multicolumn{3}{c|}{ Not admitted to ICU (n=308) } & \multicolumn{1}{c|}{$\boldsymbol{P} *$} \\
\hline & No. & Median & Range & No. & Median & Range & No. & Median & Range & \\
\hline Before HSCT & 1869 & 3 & $0-39$ & 151 & 4 & $0-18$ & 1718 & 3 & $0-39$ & 0.7 \\
\hline After HSCT & 3649 & 7 & $0-112$ & 554 & 19 & Feb-73 & 3095 & 7 & $0-112$ & $<0.0001$ \\
\hline
\end{tabular}

Table 3: Units of red blood cells of various ages (0-7, 8-14, 15-21, 22-28, 29-35 and >or 35 days) transfused to patients before and after hematopoietic stem cell transplantation (HSCT) admitted to the intensive care unit (ICU) who were alive 100 days after HSCT

\begin{tabular}{|c|c|c|c|c|}
\hline & Totaln=334(\%) & $\begin{array}{c}\text { Admitted to ICU } \\
n=27(\%)\end{array}$ & $\begin{array}{l}\text { Not admitted to } \\
\text { ICU,n=307(\%) }\end{array}$ & $p^{*}$ \\
\hline \multicolumn{5}{|l|}{ Before HSCT } \\
\hline RBC units, total & 1869 & $151(8)$ & $1718(92)$ & 0.7 \\
\hline 0-7 days & 599 (32) & $45(30)$ & $554(32)$ & 0.63 \\
\hline 8-14 days & $589(32)$ & $54(36)$ & $535(31)$ & 0.53 \\
\hline 15-21 days & 409 (22) & $25(17)$ & 384 (22) & 0.74 \\
\hline 22-28 days & $252(13)$ & $25(17)$ & 227 (13) & 0.37 \\
\hline 29-35 days & $20(1)$ & $2(1)$ & $18(1)$ & 0.86 \\
\hline 36-42 days & 0 & 0 & 0 & NA \\
\hline \multicolumn{5}{|l|}{ After HSCT } \\
\hline RBC units, total & 3649 & $554(15)$ & 3095 (85) & $<0.0001$ \\
\hline 0-7 days & 1169 (32) & $175(32)$ & 994 (32) & 0.0004 \\
\hline
\end{tabular}




\begin{tabular}{|c|c|c|c|c|}
\hline 8-14 days & $1191(33)$ & 193 (35) & 998 (32) & 0.0001 \\
\hline $15-21$ days & 810 (22) & $113(20)$ & 697 (23) & 0.0002 \\
\hline 22-28 days & $434(11.9)$ & $67(12)$ & 367 (11.9) & 0.02 \\
\hline 29-35 days & $41(1)$ & $6(1)$ & $35(1)$ & 0.02 \\
\hline 36-42 days & $4(0.1)$ & 0 & $4(0.1)$ & 0.61 \\
\hline
\end{tabular}

p value calculated by Fisher's exact test

Among the 73 patients who had been admitted to the ICU, $27(37 \%)$ were alive at HSCT day+100 and59\% were male. The median age was 52 years (range,20-70years) with a median ICU stay of 3 days (range, 1-69 days). A total of 151units of RBCs (median, 4 units; range, 0-18 units) were transfused before HSCT and 554 units (median, 19 units; range, 2-73 units) were transfused after HSCT (Table 2).Of the 324 patients not admitted to the ICU, 308 (95\%) were alive at HSCT day +100 which was significantly more ( $p=0.0001)$ than among those admitted to the ICU and $60 \%$ were male. The median age was 52 years (range, 2-72 years). Atotal of 1718units of RBCs (median, 3 units; range, 0-39 units) were transfused before HSCT and 3095units (median, 7 units; range, 0-112 units) were transfused after HSCT which was significantly different $(p=<0.0001)$ than among patients admitted to the ICU. Three of the patients not admitted to the ICU received four 4 units (two units for one patient, one unit each for the others) of RBCs> 35 days of age. None of the patients admitted to the ICU received RBCs that were in their last week of storage (35-42 days).

When the RBCs transfused were categorizedas $<28$ days or $>28$ days old, 99\% regardless of ICU admittances had received RBCs that were $<28$ days old. When the RBCs transfused were categorized as $<21$ or $>21$ days old, $83 \%$ of the patients admitted to the ICU and $85 \%$ of the patients not admitted to the ICU had received RBCs that were $<21$ days old. When the RBCs transfused were categorized as $<14$ or $>14$ days old, $66 \%$ of the patients admitted to the ICU and $63 \%$ of the patients not admitted to the ICU had received RBCs that were $<14$ days old after HSCT. RBC ages $<14$ or $>14$ days old, $<21$ days or $>21$ days or $<28$ days or $>28$ days did not significantly differ in pre-HSCT transfusions between patients admitted to the ICU and those not admitted to the ICU. However, RBC ages did significantly differ for post-HSCT transfusions between patients admitted to the ICU and patients notadmitted to the ICU for all three categories of RBC ages: $<14$ or $>14$ days $(p=0.001)$; $<21$ days or $>21$ days $(p=0.001)$ and $<28$ or $>28$ days $(p=0.02)$.

However, for post-HSCT transfusion, patients admitted to the ICU received significantly fresher RBCs than did patients not admitted to the ICU for all three categories of RBC ages $(<14$ days or $>14$ days,$<21$ days or $>21$ days and $<28$ days and $>28$ days).

Overall survival did not correlate with age of RBCs transfused in patients admitted to the ICU as well as patients not admitted to the ICU. Patients who were not admitted to the ICU who were alive at HSCT day+100 and had received the most RBCS units had the poorest overall survival rates ( $p=<0.0012$; Figure 1$)$. Similarly, for the 160 patientswith AML who were not admitted to the ICU, those who had received the most RBC units had the poorer survival rate ( $\mathrm{p}=0.0019$; Figure 2).

Overall Survival by RBCPost-TP: AML Non-ICU Patients

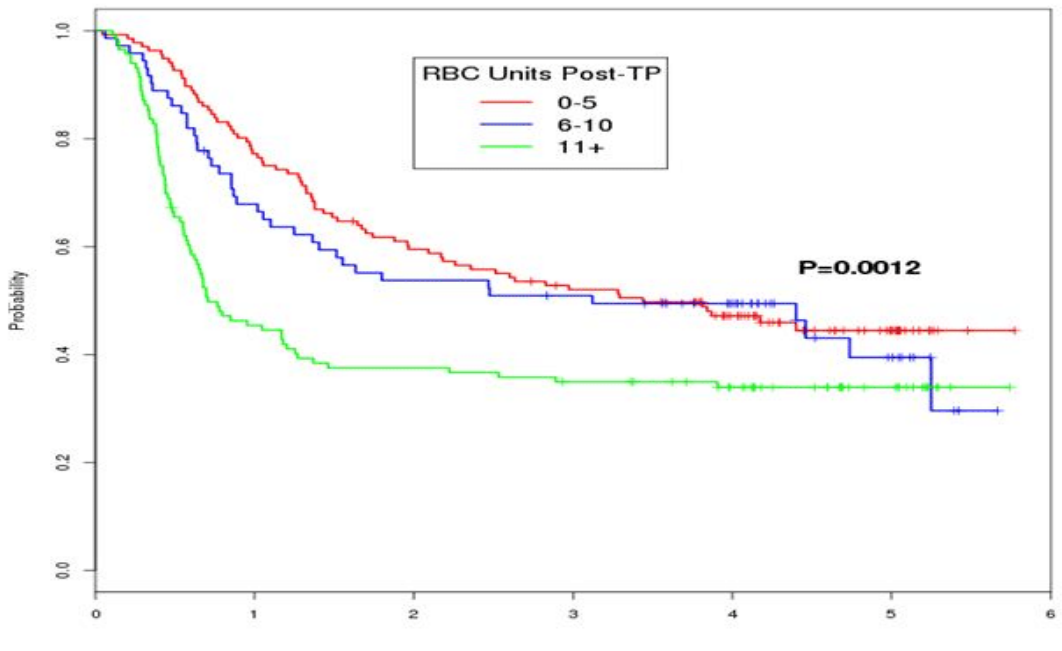

Overall Survival (Years)

$\begin{array}{lcccc} & 0-5 \mathrm{RBC} & 6-10 \mathrm{RBC} & >10 \mathrm{RBC} & \mathrm{p} \text { value } \\ \text { Total } \mathrm{n}=160(\%) & 57(36) & 40(25) & 63(30) & 0.0012 \\ \text { live } \mathrm{n}=59(\%) & 24(41) & 18(30) & 17(29) & \end{array}$

Figure 1: Kaplan-Meier estimates of overall survival according to the number of red blood cells (RBC) units transfused after hematopoietic stem cell transplantation in patients not admitted to the intensive care unit

Citation: Aung FM, Bassett RL, et al. (2017) Overall survival in hematopoietic stem cell transplantation is correlated with the Num- 


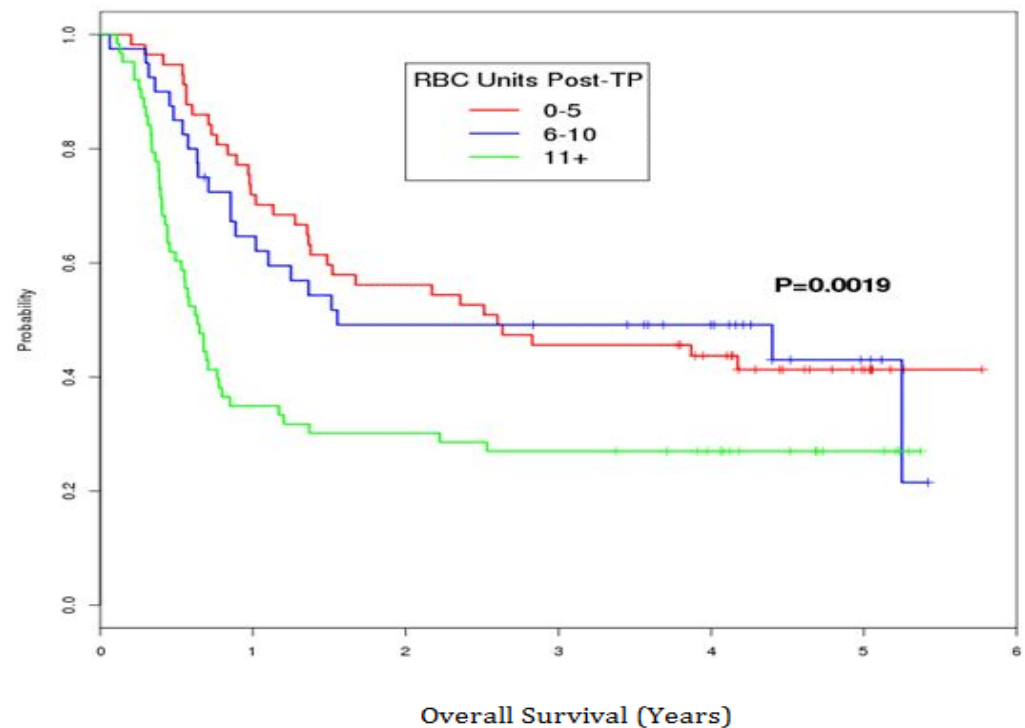

Figure 2: Kaplan-Meier estimates of overall survival according to the number of red blood cells (RBC) units transfused after hematopoietic stem cell transplantation in patients with acute myeloid leukemia who were not admitted to the intensive care unit

$\begin{array}{llllll} & 0-5 \mathrm{RBC} & 6-10 \mathrm{RBC} & >10 \mathrm{RBC} & \mathrm{p} \text { value } & \\ \text { Total } \mathrm{n}=160(\%) & 57(36) & 40(25) & 63(39) & 0.0019 \\ \text { Alive } \mathrm{n}=59(\%) & 24(41) & 18(30) & 17(29) & \end{array}$

As expected, patients admitted to the ICU had significantly poorer overall survival than those not admitted to the ICU $(p=<0.0001)$. At last follow-up, 135 of the 324 patients not admitted to the ICU were alive (median overall survival 1556 days after HSCT; range, 175-2203 days after HSCT) compared with only 2 of the 73 patients admitted to the ICU (1819 and 1901 days after HSCT) $(p=0.0001)$.

\section{Discussion}

Our retrospective analysis revealed that the number of RBCs transfused to HSCT patientshad a correlation with overall survival rather than the age of the red cells.

The age of the RBCs stored at our institution is largely dependent on the demand for transfusion, the frequent episodic inability to purchase RBC units, and the unforeseen emergency needs of our patients. The focus of our RBC inventorymanagement is not on minimizing the number of expired products but on maintaining an adequate supply for the needs of ourpatients. We do not usually practice the first-in and first-out RBC inventory optimization common at many hospitals. Forty percent of RBCs transfused in our institution are from local blood donors collected by our blood donor center; the rest are purchased from Blood Centers around the country. The age of the purchased RBCs is calculated on the basis of the expiration date and shelf-life duration of 42 days. Some purchased RBCs are irradiated, likely leading to an overestimation of the RBC age for these irradiated units, which have a shelf life of 28 days. The value of inventory reserve is different for different $\mathrm{ABO}$ groups. We maintain a higher inventory of Group O RBCs, due to the fact that only group O RBCs can be transfused to group 0 recipients and this also helps meet our needs of ourmajor ABO mismatched hematopoietic stem cell transplants.None of the RBCs transfused were volume reduced or washed.Dzik et al. 11provided a general approach for estimating the minimum mean age of RBCs at the time of issue to the patient based on considerations of demand for RBCs in patients admitted to the hospital. Studies that have shown an association between the age of RBCs and an increase in the risk of patient death have been conducted mostly at single centers and limited to specific patient groups (e.g., patients with acute cardiovascular disease or trauma )14, 15. A recent meta-analysis by Wang et al. 5 concluded that on the basis of published clinical experience, the use of older stored blood is associated with a significantly increased risk of death. We were unable to confirm that finding in our small cohort of patients who underwent HSCT. Variables such as race $(p=0.28)$, age $(<50$ years or $>50$ years) $(p=0.66)$, diagnosis $(p=0.25)$, graft source $(\mathrm{p}=0.43)$, HLA match grade $(\mathrm{p}=0.18)$,pre-conditioning therapy $(\mathrm{p}=0.48)$ and $\mathrm{ABO}$ matching $(\mathrm{p}=0.4)$ was not associated with overall survival (Figures 3-8). However, we did not adjust for possible independent confounding variables such as other comorbidities, illness-severity scores, prior transplantation history orreceipt of certain lipophilic drugs on RBCs and did not compare patients with identical risk factors for the outcome that would allow for correction.Aged RBCs that were stored for 35 to 42 days was not one of the confounding variables in our studymainly due to the high volume of transfusions that take place daily at our institution.Thus, the findings in our retrospective analysis arelimited by potential confounding by indication. 17Studies of the effects of RBC age on outcomes have yielded conflicting results. 


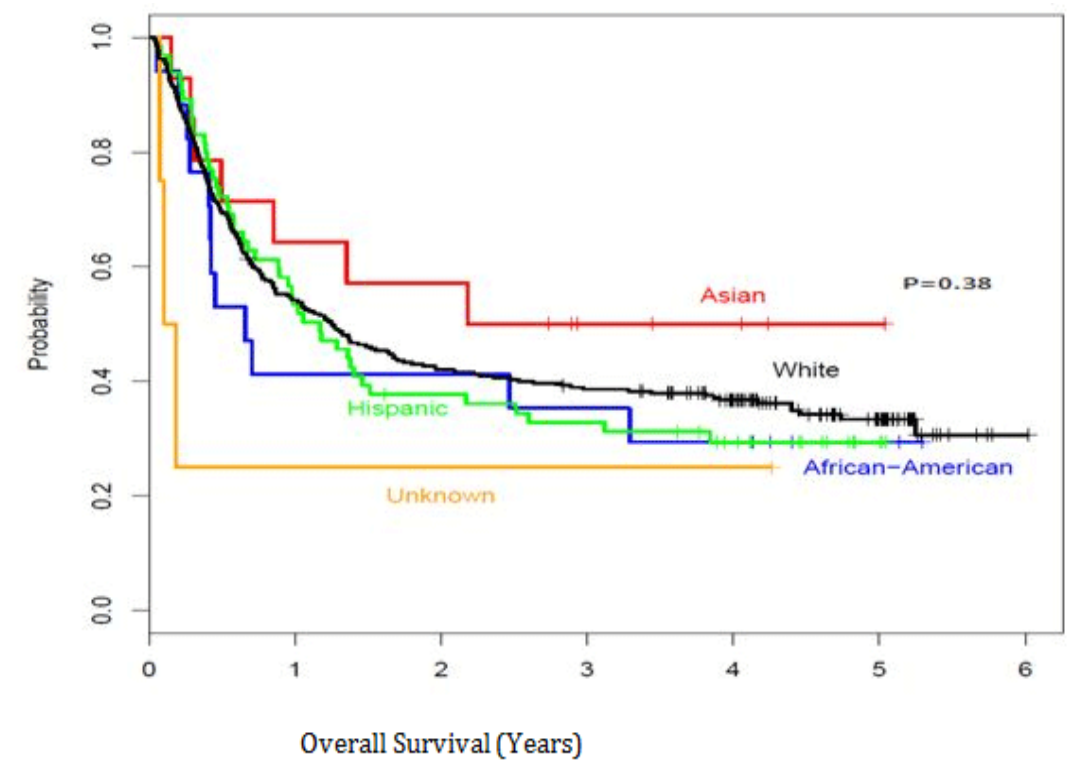

Figure 3: Kaplan-Meier estimates of overall survival by race/ethnicity

Figure 3: Kaplan-Meier estimates of overall survival by race/ethnicity
\begin{tabular}{lccccc}
\multicolumn{7}{c}{ Caucasian } & African American & Hispanic & Asian & Unknownp value \\
Total $\mathrm{n}=397(\%)$ & $397(75)$ & $17(4) 65(16)$ & $14(4)$ & $4(1)$ & 0.38 \\
Alive $\mathrm{n}=137(\%)$ & $104(76)$ & $5(4)$ & $20(14)$ & $7(5)$ & $1(1)$
\end{tabular}

Overall Survival by Age: All Patients

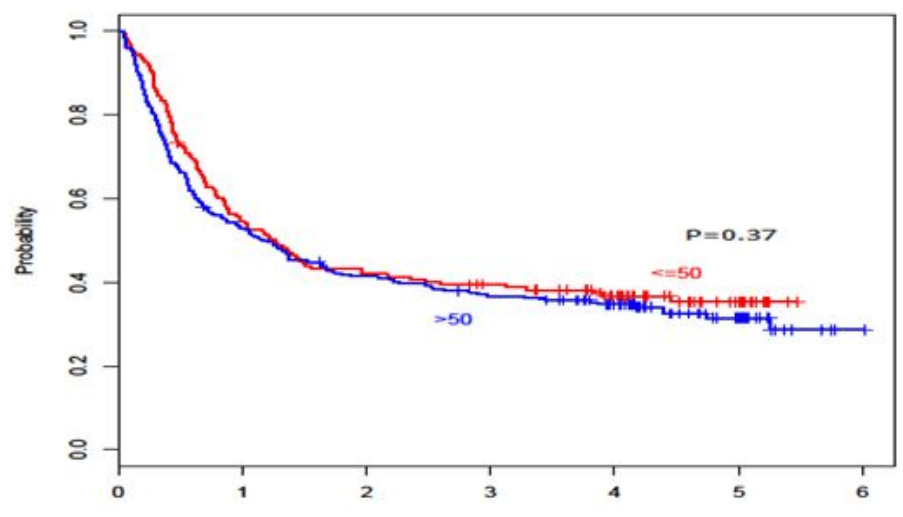

Overall Survival (Years)

Figure 4: Kaplan-Meier estimates of overall survival by age ( $<50$ years or $>50$ years)

$\begin{array}{llcr} & \text { Age }<50 & \text { Age }>50 & p \text { value } \\ \text { Total } \mathrm{n}=397(\%) & 143(36) & 254(64) & 0.37 \\ \text { Alive } \mathrm{n}=437(\%) & 62(45) & 74(54) & \end{array}$

In a large-scale retrospective population study, Edgrenet al.16 found a 5\% excess mortality in both short- and long-term analyses when blood stored for more than 30 days was transfused. In contrast,Yap et al.18 concluded that the age of transfused RBCs was not associated with early mortality and morbidity in their review of 6370 consecutive patients who underwent non emergent cardiac surgery and had received at least two units of 2 RBCs. In their recent study of 8416 patients admitted to the ICU who had received a median of four units of RBCs, Aubronet al.19 found that RBC age was not independently associated with mortality. Kekre et al.20 in their analysis of 640 patients who

underwent HSCT, reported that RBC storage time did not appear to influence clinical outcome and patients with increased RBC transfusion requirements had greater toxicity after HSCT. In the RECESS13 clinical trials, transfusion of RBCs stored for 10 days or lesswas not superior to the transfusion of RBCs stored for 21 days or more among patients aged 12 years or older whounderwent cardiac surgery. Similar findings were noted by the ABLE investigators and the Canadian Critical Care Trials group as well as in the ARIPI Randomized Trail. 21-22 in a most recent randomized controlled trial of 20858 patients, Heddle et al.23 concluded that among patients in a general hospital population 
Overall Survival by Diagnosis: All Patients

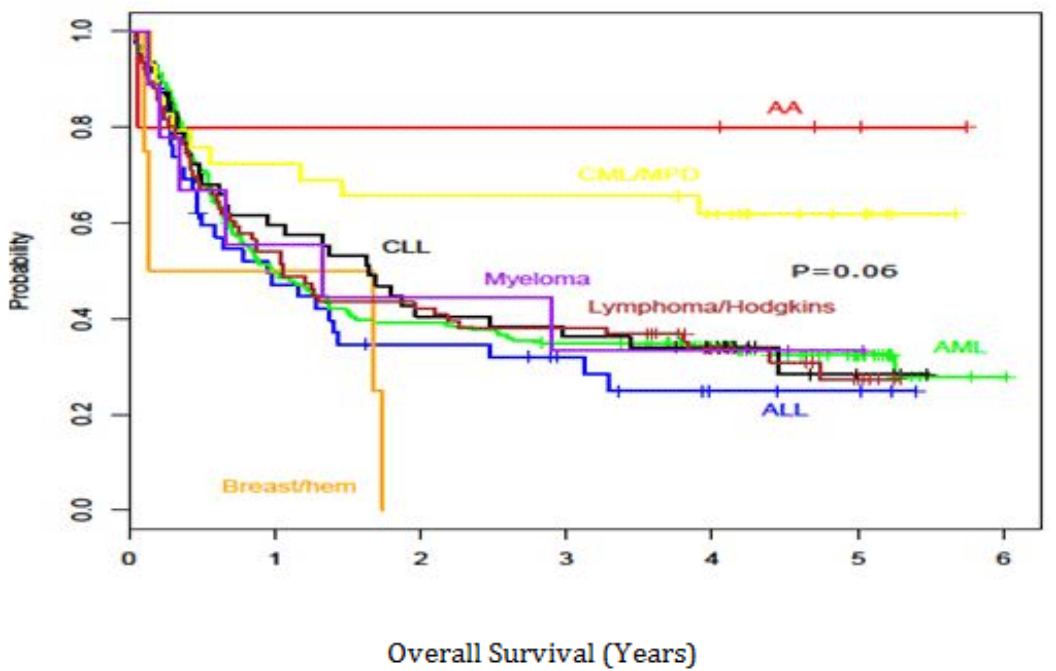

Figure 5: Kaplan-Meier estimates of overall survival by diagnosis

AMLCML/MPDALLCLL

Total $\mathrm{n}=397(\%) 185$ (47)

Aliven=137 (\%) $61(45)$
Lymph/Hodgkin's Myeloma
AA Non-hematologic
29 (7) $42(11) \quad 47(12)$
$76(19) 9(2) 5(1)$
$18(13) \quad 12(9) \quad 15(11) \quad 24(18) \quad 3(2) \quad 4(3) \quad 0()$
$p$ value

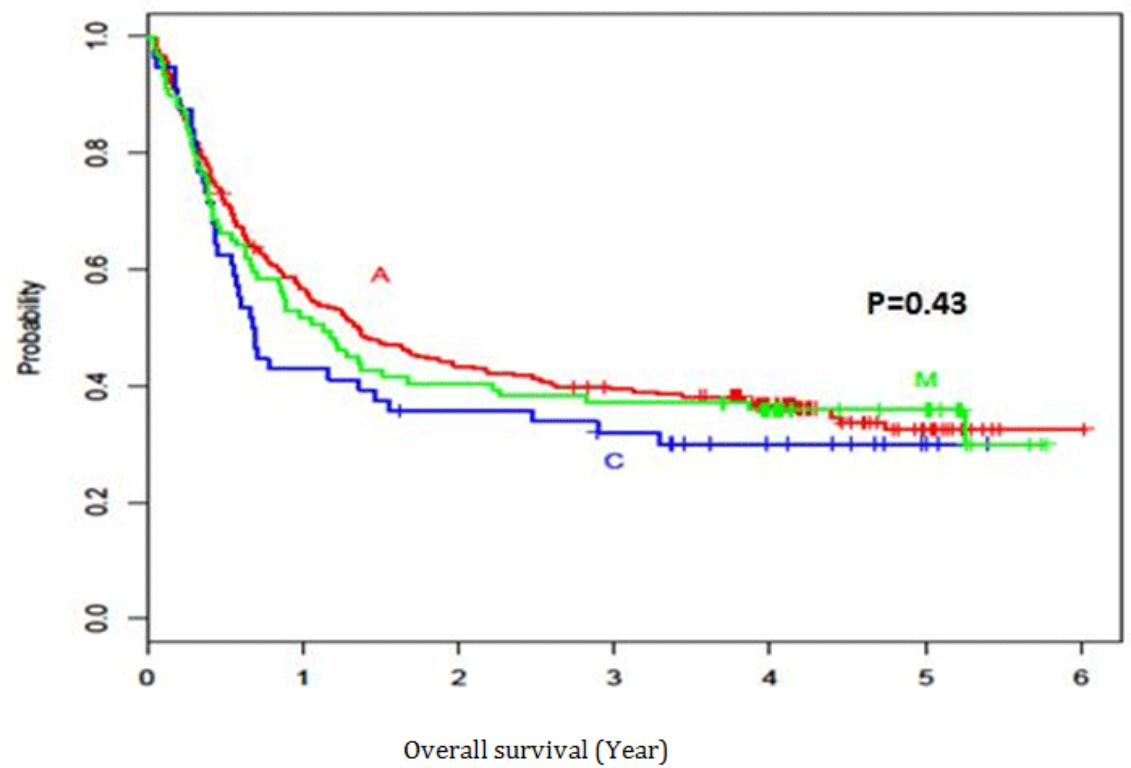

Figure 6: Kaplan-Meier estimates of overall survival by graft source

$\begin{array}{cccc}\text { Peripheral stem cell } & \text { Marrow } & \text { cords } & p \text { value } \\ 227(68) & 67(20) & 41(12) & 0.43 \\ 89(65) & 31(23) & 17(12) & \end{array}$

Total $n=397(\%)$

$89(65)$

$31(23)$

$17(12)$ 
Overall survival by Myeloablative Regimen: All Patient

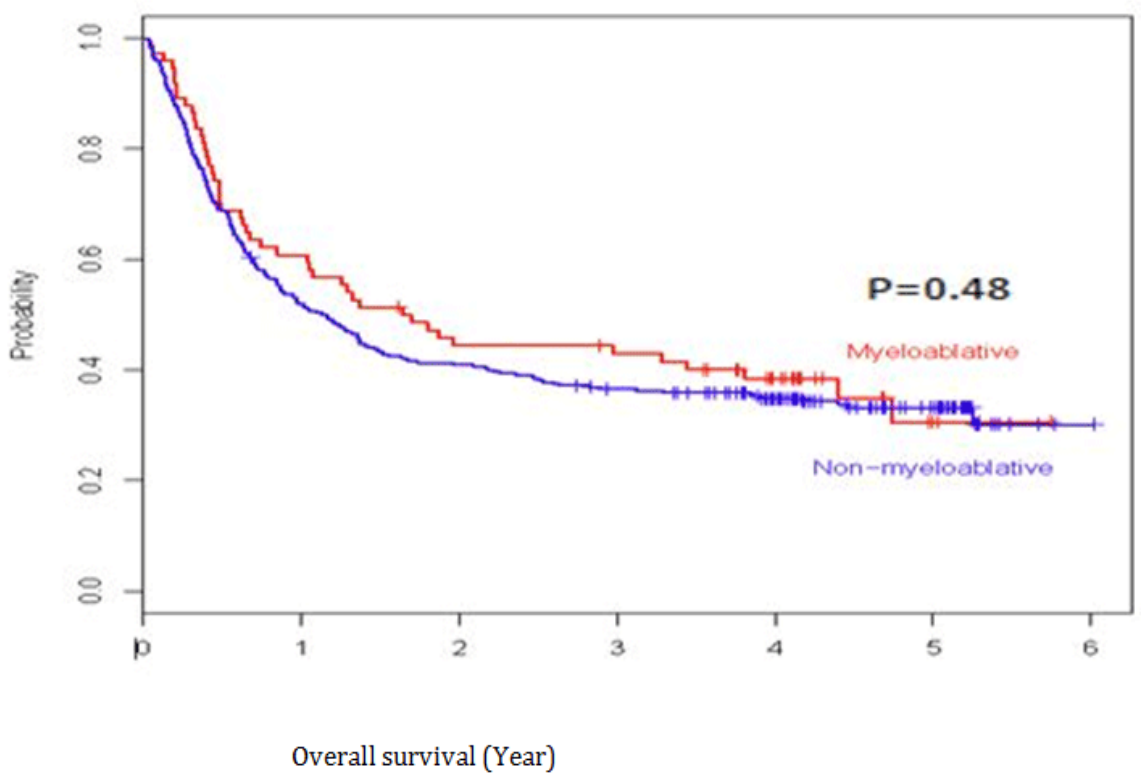

Figure 7: Kaplan-Meier estimates of overall survival by pre-conditioning therapy (myeloablative-Reduced intensity conditioning/non-myeloablative therapy)

$\begin{array}{lccc} & \text { Myeloablative } & \text { Non-Myeloablative } & p \text { value } \\ \text { Total } \mathrm{n}=397(\%) & 323(81) & 74(19) & 0.48 \\ \text { Alive } \mathrm{n}=137(\%) & 110(80) & 27(20) & \end{array}$

Overall survival By ABO Matching: All Patients

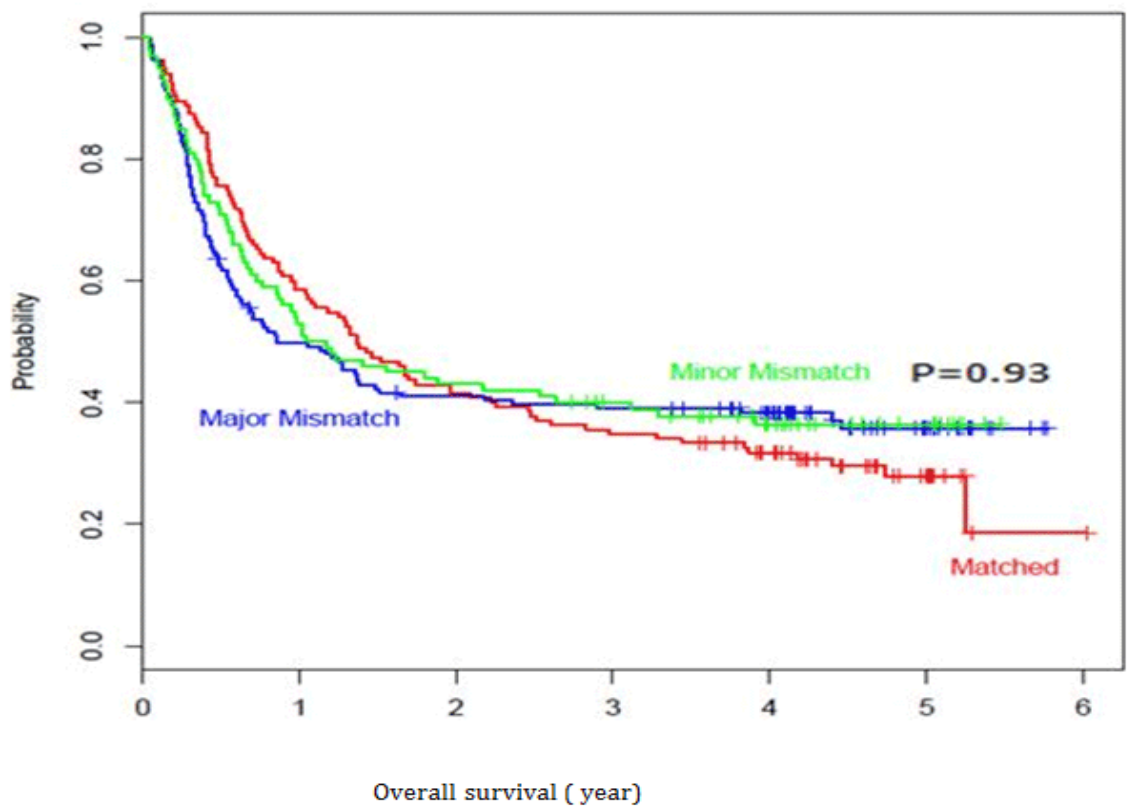

Figure 8: Kaplan-Meier estimates of overall survival by ABO matching

$\begin{array}{lcccc} & \text { ABO Matched } & \text { Major ABO Mismatch Minor ABO Mismatch } & p \text { value } \\ \text { Total } n=397(\%) & 135(34) & 63(41) & 99(25) & 0.93 \\ \text { Alive } n=135(\%) & 38(28) & 61(45) & 36(27) & \end{array}$


there was no significant difference in rate ofdeath among those who received freshest available blood transfusions than those who received transfusions of the oldest available blood.

We conclude by saying that overall survival did not correlate with age of RBCs transfused in patients admitted to the ICU as well as in patients not admitted to the ICU before and after HSCT. In addition, our study evaluated the age of RBCs transfused not only post-transplant but also pre-transplant in our HSCT patients which was not performed in previous studies. Our findingsare consistent with recent findings by various investigators studying the association of RBC age with patient mortality in critically ill patients, patients undergoing cardiac surgery or HSCT and in premature infants receiving $\mathrm{RBC}$ transfusions that $\mathrm{RBC}$ age is not correlated with an increase in short term mortality.

\section{FUNDING}

The reporting of the statistical analyses was supported in part by the Cancer Center Support Grant (NCI Grant P30 CA016672). Conflicts of Interest Disclosures:The authors have no disclosures.

\section{Contributions}

FMA designed the research, collected, analyzed, interpreted the data and wrote the paper. RB performed the statistical analysis. BL collaborated on the analysis and the interpretation. $\mathrm{CH}$ performed part of the research. $\mathrm{CH}, \mathrm{EJF}$ and IK analyzed and reviewed the data.

\section{References}

1. Rapoport S Dimensional,Osmotic and Chemical Changes of Erythrocytes in Stored Blood. I. Blood preserved in sodium citrate, neutral and Acid Citrate-Glucose (ACD) Mixtures. J Clini Invest. 1947;26(4):591-615 Doi: $10.1172 / J C I 101843$

2. Gabrio BW and Finch C A. Erythrocyte Preservation. I. The relation of the Storage lesion to In Vivo Erythrocyte Senescence. J. Clin. Invest. 1954;33:242-246. Doi: 10.1172/JCI102891

3. Gabrio BW, Stevens AR Jr and Finch CA. Erythrocyte Preservation. II. A Study of Extra-Erythrocyte Factors in the Storage of Blood in AcidCitrate-Dextrose. J Clini Invest. 1954;33(2):247-51. Doi: 10.1172/ JCI102892

4. Wolfe LC, Byrne AM and Lux SE. Molecular defect in the Membrane Skeleton of Blood bank-stored Red Cells. J Clini Invest. 1986 78(6):1681-1686. Doi: doi: 10.1172/JCI112762

5. Wang D, Sun J, Solomon SB, Klein HG and Natanson C. Transfusion of older stored blood and risk of death: a meta-analysis. Transfusion 2012:;52(6):1184-1195. Doi: doi: 10.1111/j.1537-2995

6. Koch CG, Lang L, Sessler DI, Figueroa P, Hoeltge GA, Mihaljevic T et al. Duration of red-cell storage and complications after cardiac surgery. N Engl J Med. 2008;358:1229-39. Doi: 10.1056/NEJMoa070403

7. Kaestner L and Bodganova A. Regulation of red cell life-span, erythropoiesis, senescence and clearance. Frontiers in Physiology 2014:5;269. Doi: 10.3389/fphys.2014.00269

8. Bosman GJ, Lasonder E, Groenen-Dopp YA, Willekens FL and Wierre JM. The proteome of erythrocyte-derived microparticles from plasma: new clues for erythrocyte aging and vesiculation. J Proteomics.2012:76;203-210. Doi: 10.1016/j.jprot.2012.05.031
9. Flatt JF, Bawazir WM and Bruce LJ. The involvement of cation leaks in the storage lesion of red blood cells. Frontiers in Physiology. 2014: 5;112. Doi: $10.3389 /$ fphys.2014.00214

10.Pavenski K, Saidenburg E, Lavoie M and Brach DR.Red Blood Cell Storage Lesions and Related Transfusion Issues: A Canadian Blood Services Research and Development Symposium. Transfus Med Rev. 2012:26;68-84. Doi: 10.1016/j.tmrv.2011.07.003

11.Dzik WH, Beckman N, Murphy MF, Delaney M, Flanagan P, Fung M et al. Factors affecting red blood cell storage at the time of transfusion. Transfusion . 2013;53(12):3110-3119. Doi: DOI: 10.1111/ trf.12171

12.Hod EA, Zhang N, Sokol SA, Wojczyk BS, Francis RO, Ansaldi D et al. Transfusion of red blood cells after prolonged storage produces harmful effects that are mediated by iron and inflammation. Blood. 2010;115:4284-4292. Doi: 10.1182/blood-2009-10-245001

13.Zolla L, D’Alessandro A, Rinalducci S, D’Amici GM, Pupella S et al. Classic and alternative red blood cell storage strategies: seven years of " -omics" investigations. Blood Transfus. 2015;13:21-31. Doi: $10.2450 / 2014.0053-14$

14.Garraund 0. Effect of "old" versus "fresh" transfused red blood cells on patients' outcome: probably more complex than appears. J Thorac Dis. 2017;9:E146-148. Doi: 10.21037/jtd.2017.02.03

15.Steiner ME, Ness PM, Assmann SF, Triulzi DJ, Sloan SR, Delaney M et al. Effects of Red-Cell Storage Duration on Patients Undergoing Cardiac Surgery. NEJM. 2015;372 :1419-1429. Doi: 10.1056/NEJMoa1414219

16.Edgren Gustaf, Kamper-Jorgensen M, Eloranta S, Rostgaard K, Custer B, Ullum $\mathrm{H}$ et al. Duration of red blood cell storage and survival of transfused patients. Transfusion 2010: 50;1185-95. Doi: 10.1111/j.1537-2995.2010.02583.x

17.Middleburg RA, van de Watering LMG and Van der Bom JG. Blood Transfusions: good or bad? Confounding by indication, an underestimated problem in clinical transfusion research. Transfusion 2010:50(6);1181-83. Doi: 10.1111/j.1537-2995.2010.02675.x

18.Yap CH, Lau L, Krishnaswamy K, Gaskell M and Yii M. Age of Transfused Red Cells and Early Outcomes after Cardiac Surgery. Ann Thorac Surg 2008:86;554-559. Doi:10.1016/j.athoracsur.2008.04.040

19.Aubron C, Bailey M, McQuilten Z, Pilcher D, Hegarty C, MartinelliAet al. Duration of red blood cells storage and outcome in critically ill patients. J Crit Care.2014:29(3); 476. Doi: 10.1016/j.jcrc.2014.01.006

20.Kekre N, Chou A, Tokessey M, Tinmouth A, Tay J and Allan DS. Storage time of transfused red blood cells and impact on clinical outcome in hematopoietic stem cell transplantation.Transfusion.2011:51(11); 2488-2494. Doi: 10.1111/j.1537-2995.2011.03166.x

21.Fergusson DA, Hebert P, Hogan Dl, LeBel L, Rouvinez-Bouali N, Symth JA et al. Effect of fresh red blood cell transfusions on clinical outcomes in premature, very low-birth-weight infants: the ARIPI randomized trial. JAMA 2012;308(14):1443-1451. Doi: 10.1001/2012.jama.11953

22.Lacroix J, Hebert PC, Fergusson DA, Tinmouth A, Cook DJ, Marshall JC et al. Age of transfused blood in critically ill adults. N Engl J Med .2015;372-1410-1418. Doi: 10.1056/NEJMoa1500704

23. Heddle N, Cook RJ, Arnold DM, Liu Y, Barty R, Crowther MA et al. Effect of Short-Term vs. Long-Term Blood Storage on Mortality after Transfusion. N Eng J of Med. 2016;375(20):1937-1945. Doi:10.1056/ NEJMoa 160914 